\title{
Health Information Technology Needs Help from Primary Care Researchers
}

\author{
Alex H. Krist, MD, MPH, Lee A. Green, MD, MPH, Robert L. Phillips, MD, MSPH, \\ John W. Beasley, MD, Jennifer E. DeVoe, MD, DPhil, Michael S. Klinkman, MD, MS, \\ John Hughes, MD, Jon Puro, MPA, HA, Chester H. Fox, MD, and \\ Tim Burdick, MD, MS; for the NAPCRG Health Information Technology Working \\ Group
}

While health information technology (HIT) efforts are beginning to yield measurable clinical benefits, more is needed to meet the needs of patients and clinicians. Primary care researchers are uniquely positioned to inform the evidence-based design and use of technology. Research strategies to ensure success include engaging patient and clinician stakeholders, working with existing practice-based research networks, and using established methods from other fields such as human factors engineering and implementation science. Policies are needed to help support primary care researchers in evaluating and implementing HIT into everyday practice, including expanded research funding, strengthened partnerships with vendors, open access to information systems, and support for the Primary Care Extension Program. Through these efforts, the goal of improved outcomes through HIT can be achieved. (J Am Board Fam Med 2015;28:306-310.)

\section{The State of Health Information Technology in Primary Care}

Health information technology (HIT) has forever changed how clinicians practice medicine and how patients experience care. Fueled by meaningful use incentives and the patient-centered medical home movement, primary care leads the way in adopting and implementing new technologies. More than

Submitted 28 August 2014; revised 15 December 2014; accepted 8 January 2015.

From the Department of Family Medicine and Population Health, Virginia Commonwealth University, Richmond (AHK, RLP); the Department of Family Medicine, University of Alberta, Edmonton, Alberta, Canada (LAG); the American Board of Family Medicine, Washington, DC (RLP); the Departments of Family Medicine and Industrial and Systems Engineering, University of Wisconsin, Madison (JWB); OCHIN, Portland, OR (JED, JP, TB); the Departments of Family Medicine and Medical Informatics and Clinical Epidemiology, Oregon Health \& Science University, Portland (JED, TB); the Department of Family Medicine, University of Michigan, Ann Arbor (MSK); the Department of Family Medicine, McGill University, Montreal, Quebec Canada (JH); and the Department of Family Medicine, University at Buffalo, Buffalo, NY (CHF).

Funding: none.

Conflict of interest: none declared.

Corresponding author: Alex H Krist MD, MPH, PO Box 980251, Richmond VA 23298-0251 (E-mail: ahkrist@vcu. edu). two thirds of primary care practices have an electronic health record (EHR), and $60 \%$ of primary care clinicians have participated in meaningful use. $^{1-4}$

While early systems mainly supported business operations such as coding and claims reporting ("business as usual"), the transformative goal of HIT is to improve care delivery and health outcomes. ${ }^{5,6}$ Successful first steps in support of this transformation have included defining core content to include in patients' records, identifying basic clinical data classifications, creating mechanisms to exchange health information, and standardizing EHR functionality for use by all clinicians (eg, computerized provider order entry, medication reconciliation, secure messaging, and the provision of after-care summaries). ${ }^{7,8}$ As a result, EHRs have increased the availability of health data and improved some elements of documentation quality and consistency. ${ }^{9}$ Some health information exchanges reduce redundant testing and improve care coordination. ${ }^{9,10}$ Computerized order entry, prompts, and alerts are beginning to reduce preventable errors in some health systems. ${ }^{11}$ When used, electronic communication improves access to 
care and patient satisfaction. ${ }^{12}$ Patient portals can personalize health recommendations, engage patients in care, and increase the delivery of recommended services. ${ }^{13-16}$ Mobile health is showing promise in promoting communication and health behavior change. ${ }^{17,18}$

Despite these advances, much more is needed from HIT to be truly transformative. ${ }^{16,19}$ The early successes described above have been reported primarily in research settings and exemplar health systems, not typical community-based practices. Few clinicians believe that their EHR improves care delivery or outcomes, citing both limited functionality and extra work as clerical and data entry tasks are added to already overburdened workloads. ${ }^{19-23}$ Patients worry about their medical records going digital, expressing fears about privacy and skepticism that HIT will result in better, more efficient care. ${ }^{24,25}$ The introduction of a computer in the examination room detracts from clinicianpatient communication and relationship building. ${ }^{26}$ While specific documentation elements may be improving, the importance of patient narrative is increasingly ignored. ${ }^{9,27}$

\section{Need for Primary Care Research to Inform HIT}

Primary care cannot escape HIT. Information is the cornerstone of good clinical care-information for clinicians, care teams, and patients-and HIT is the means of organizing, documenting, accessing, and sharing information, as well as measuring outcomes. What primary care needs is a voice to inform the design and implementation of HIT. Research can give primary care its voice, and primary care researchers provide a unique set of skills, resources, and perspectives to inform HIT.

Practicing clinicians and patients have the clearest understanding of what they need from HIT and should be shaping the national HIT research agenda. In 2012 the HIT Working Group for the North American Primary Care Research Group, with support from the American Academy of Family Physicians, American Academy of Pediatrics, and American Board of Family Medicine, worked with national primary care leaders and 148 clinicians from 3 practice-based research networks (PBRNs) to identify specific ways in which HIT could better support the delivery of primary care. ${ }^{28}$ High-priority items included the following:
1. Human factors design to ensure that technology supports users' needs

2. Enhanced extraction, interpretation, prioritization, and presentation of critical health information for individual patients at the point of care and for a clinician's patient panel

3. Advanced information exchange to coordinate care across clinicians and settings

4. Greater patient engagement tools and supports

5. Population management innovations, including predictive analytics, to proactively deliver care outside of traditional office visits

6. Reduced documentation burden

7. Integration of care across settings, particularly between the health care setting and community

These priorities overlap with research priorities recently published by the Agency for Healthcare Research and Quality (AHRQ) and a recent report outlining frustrations with how meaningful use has been implemented. ${ }^{29,30}$

Primary care researchers have both the expertise and relationships to effectively engage clinicians, patients, and stakeholders in HIT research. The Patient Center Outcomes Research Institute is bringing national attention to patient and stakeholder engagement in all aspects of research, and a growing body of evidence is demonstrating how engagement enhances the science and success of research. ${ }^{31}$ The tasks of providing the full spectrum of primary care-acute care, chronic disease management, preventive services, and psychosocial services-are enormously complex. The workflow, information needs, and communication processes must be described and studied in partnership with clinicians and patients to understand how HIT can effectively support their needs. Similarly, the practice-level tasks of using data to optimize the care of whole panels of patients must also be studied in partnership with practices learning to redesign care to support population needs.

To effectively conduct real-world HIT research, infrastructure and robust community "laboratories" such as PBRNs are needed. PBRNs exist in every state and can connect researchers to clinicians and patients engaged in the day-to-day delivery of care. By design, PBRNs are grounded in, informed by, and intended to improve practice. ${ }^{32}$ Primary care research also has a culture of multidisciplinary research and partnerships with experts in other fields that are uniquely positioned to inform the 
evidence-based design and use of technology. ${ }^{33}$ Partnerships between clinicians, patients, communities, informaticists, systems engineers, and researchers are needed to develop, test, and inform the next generation of HIT. Blending the disciplines of health care, industrial systems, cognitive task analysis, and corporate change can further guide HIT research. ${ }^{34-37}$ These multidisciplinary approaches are exemplified by the Improving Care Through Industrial and Systems Engineering (IPrACTISE) collaborative, which is identifying and developing system design solutions to common primary care problems, including HIT. ${ }^{38}$

HIT needs high-quality dissemination and implementation research-another domain in which primary care researchers can excel. ${ }^{39}$ To ensure use, HIT systems need to be simplified, both in terms of design and implementation, while still meeting users' documentation, information sharing, decision-making, and care delivery needs.

\section{Policy Needs to Support Primary Care HIT Research}

To conduct research necessary to improve HIT, primary care researchers will need help from policymakers, funders, and industry. Federal and state governments currently lack support for the field research that needs to occur in primary care. Although more than half of all visits made to any setting occur in primary care, most HIT research funding has been directed to hospitals. ${ }^{40}$ The type of HIT research that primary care needs does not fit neatly into traditional National Institutes of Health funding mechanisms. Funding from the Office of the National Coordinator has focused largely on getting EHRs into the hands of clinicians, and while successful in that goal, it has done little to support research. The Patient Centered Outcomes Research Institute is an excellent source of funding for patient and stakeholder engagement research, although no requests for proposals currently focus on HIT. To date, AHRQ has been the main source of primary care HIT research support; while critically important, however, it is not sufficient.

Because HIT is evolving at a furious pace, rapid, relevant, and pragmatic funding mechanisms are needed to support primary care HIT research. ${ }^{41}$ This includes rapid market consolidation that often means primary care clinics have to jettison their
EHRs for those adopted by hospitals. One potential solution to support rapid, relevant, research is for HIT vendors to partner with and fund primary care research as well as to support open-source applications that can seamlessly integrate with their systems. This would benefit both researches and vendors. Another solution that would give primary care greater control over HIT is for clinicians and researchers to pursue advanced training in informatics. ${ }^{42}$

The Primary Care Extension Program, authorized by the Affordable Care Act and currently expanding under AHRQ IMPaCT grants, can serve as a catalyst for promoting primary care HIT research and innovation. ${ }^{43}$ The Primary Care Extension Program is modeled after the USDA Cooperative Extension and is partially being tested by HIT regional extension centers, with the intended goals of:

1. identifying innovators and highly functioning HIT systems;

2. facilitating in vivo evaluation of these systems for transferable lessons;

3. attempting to reproduce innovations in PBRNs; and

4. facilitating broad dissemination of innovations and training of clinicians.

\section{Conclusion}

Health care has been affected by an explosion of technology and data that must be harnessed quickly and effectively. The need for evidence to inform the development and effective use of innovative and useful HIT is greater than ever. The primary care community is uniquely poised to answer this call to action. By building on our effective PBRNs and developing robust primary care HIT research infrastructure, new knowledge can be generated to rapidly accelerate the use of technology and data to improve patient and population health, decrease costs, and improve the effectiveness and joy of care.

\section{References}

1. Schoen C, Osborn R, Squires D, et al. A survey of primary care doctors in ten countries shows progress in use of health information technology, less in other areas. Health Aff (Millwood) 2012;31:2805-16.

2. US Department of Health \& Human Services. Doctors and hospitals' use of health IT more than doubles since 2012. August 5, 2013. Available from: 
http://www.hhs.gov/news/press/2013pres/05/20130522a. html. Accessed March 6, 2015.

3. Hsiao CJ, Jha AK, King J, Patel V, Furukawa MF, Mostashari F. Office-based physicians are responding to incentives and assistance by adopting and using electronic health records. Health Aff (Millwood) 2013;32:1470-7.

4. Xierali IM, Hsiao CJ, Puffer JC, et al. The rise of electronic health record adoption among family physicians. Ann Fam Med 2013;11:14-9.

5. Blumenthal D, Tavenner M. The "meaningful use" regulation for electronic health records. N Engl J Med. 2010;363(6):501-4.

6. Centers for Medicare and Medicaid Services. CMS Medicare and Medicaid EHR incentive programs: milestone timeline. Available from: http://www. cms.gov/Regulations-and-Guidance/Legislation/ EHRIncentivePrograms/Downloads/EHRIncent Progtimeline508V1.pdf. Accessed March 6, 2015.

7. HealthIT.gov. Consolidated CDA overview. Available from: http://www.healthit.gov/policy-researchersimplementers/consolidated-cda-overview. Accessed March 6, 2015.

8. Office of the National Coordinator for Health Information Technology (ONC) Department of Health and Human Services. 2014 Edition Electronic Health Record certification criteria: revision to the definition of "common meaningful use (MU) data set" Fed Regist 2013;45:65,884-7.

9. Nguyen L, Bellucci E, Nguyen LT. Electronic health records implementation: An evaluation of information system impact and contingency factors. Int J Med Inform 2014;83:779-96.

10. Lammers EJ, Adler-Milstein J, Kocher KE. Does health information exchange reduce redundant imaging? Evidence from emergency departments. Med Care 2014;52:227-34.

11. Nuckols TK, Smith-Spangler C, Morton SC, et al. The effectiveness of computerized order entry at reducing preventable adverse drug events and medication errors in hospital settings: a systematic review and meta-analysis. Syst Rev 2014;3:56.

12. Bishop TF, Press MJ, Mendelsohn JL, Casalino LP. Electronic communication improves access, but barriers to its widespread adoption remain. Health Aff (Millwood) 2013;32:1361-7.

13. Krist AH, Woolf SH, Rothemich SF, et al. Interactive preventive health record to enhance delivery of recommended care: a randomized trial. Ann Fam Med 2012;10:312-9.

14. Krist AH, Woolf SH, Rothemich SF, et al. An interactive preventive health record to enhance delivery of recommended care: a randomized trial. Supplemental appendix. Ann Fam Med 2012;10:312-9. Available from: http://www.annfammed.org/content/ 10/4/312/suppl/DC1. Accessed March 6, 2015.

15. Krist AH, Woolf SH. A vision for patient-centered health information systems. JAMA 2011;305:300-1.
16. Goldzweig CL, Orshansky G, Paige NM, et al. Electronic patient portals: evidence on health outcomes, satisfaction, efficiency, and attitudes: a systematic review. Ann Intern Med 2013;159:677-87.

17. Fanning J, Mullen SP, McAuley E. Increasing physical activity with mobile devices: a meta-analysis. J Med Internet Res 2012;14:e161.

18. Free C, Phillips G, Watson L, et al. The effectiveness of mobile-health technologies to improve health care service delivery processes: a systematic review and meta-analysis. PLoS Med 2013;10:e1001363.

19. Edsall RL, Adler KG. User satisfaction with EHRs: report of a survey of 422 family physicians. Fam Pract Manag 2008;15:25-32.

20. Beasley JW, Wetterneck TB, Temte J, et al. Information chaos in primary care: implications for physician performance and patient safety. J Am Board Fam Med 2011;24:745-51.

21. Fiegel C. Stage 2 meaningful use rules sharply criticized by physicians. American Medical News, May 14, 2012. Available from: http://www.amednews. com/article/20120514/government/305149959/1/. Accessed March 6, 2015.

22. Lewis Dolan P. Doctor's love-hate relationship with EHRs. American Medical News. May 7, 2012. Available from: http://www.amednews.com/article/20120507/ business/305079968/4/. Accessed March 6, 2015.

23. McDonald CJ, Callaghan FM, Weissman A, Goodwin RM, Mundkur M, Kuhn T. Use of internist's free time by ambulatory care electronic medical record systems. JAMA Intern Med. 2014;174:1860-3.

24. Lewis Dolan P. Patients worried about medical records going digital. American Medical News, August 20, 2012. Available from: http://www.amednews. com/article/20120820/business/308209965/6/ \#relatedcontenthed/. Accessed March 6, 2015.

25. Vodicka E, Mejilla R, Leveille SG, et al. Online access to doctors' notes: patient concerns about privacy. J Med Internet Res 2013;15:e208.

26. Street RL Jr, Liu L, Farber NJ, et al. Provider interaction with the electronic health record: the effects on patient-centered communication in medical encounters. Patient Educ Couns 2014;96:315-9.

27. Hirschtick RE. A piece of my mind. Copy-and-paste. JAMA 2006;295:2335-6.

28. Krist AH, Beasley JW, Crosson JC, et al. Electronic health record functionality needed to better support primary care. J Am Med Inform Assoc 2014.

29. Health IT research priorities to support the health care delivery system of the future. Rockville, MD: Agency for Healthcare Research and Quality. 2014; 21:764-71.

30. JASON, The MITRE Corporation. A robust health data infrastructure. AHRQ publication no. 14-0041EF. Rockville, MD: Agency for Healthcare Research and Quality; 2014.

31. Woolf SH, Krist AH. What the research community can learn from patient and stakeholder engagement. 
October 1, 2014. Available from: http://www. pcori.org/blog/what-research-community-can-learnpatient-and-stakeholder-engagement. Accessed March 6, 2015.

32. Westfall JM, Mold J, Fagnan L. Practice-based research-"Blue Highways" on the NIH roadmap. JAMA 2007;297:403-6.

33. Reid PP, Compton WD, Grossman JH, Fanjiang G. Building a better delivery system: a new engineering/ health care partnership. Washington, DC: National Academies Press; 2005.

34. Crandall B, Klein GA, Hoffman RR. Working minds: a practitioner's guide to cognitive task analysis. Cambridge, MA: MIT Press; 2006.

35. Potworowski G, Green LA. Cognitive task analysis: methods to improve patient-centered medical homes by understanding and leveraging its knowledge work. AHRQ publication no. 13-0023-EF. Rockville, MD: Agency for Healthcare Research and Quality; 2013.

36. Greenhalgh T. Role of routines in collaborative work in healthcare organisations. BMJ 2008;337: a2448.

37. Becker MC. Organizational routines: a review of the literature. Indust Corporate Change 2004;13: $643-77$.
38. Beasley JW, Carayon P, Smith MA, eds. Improving quality and efficiency of primary care through industrial and systems engineering-a white paper. 2013. Available from: http://www.fammed.wisc.edu/sites/ default/files/webfm-uploads/documents/research/ipractise/i-practise-white-paper.pdf/. Accessed March 6, 2015.

39. Heintzman J, Gold R, Krist A, Crosson J, Likumahuwa S, DeVoe JE. Practice-based research networks (PBRNs) are promising laboratories for conducting dissemination and implementation research. J Am Board Fam Med 2014;27:759-62.

40. Hsiao CJ, Cherry DK, Beatty PC, Rechtsteiner EA. National Ambulatory Medical Care Survey: 2007 summary. Natl Health Stat Rep 2010;(27):1-32.

41. Glasgow RE, Kessler RS, Ory MG, Roby D, Gorin SS, Krist A. Conducting rapid, relevant research: lessons learned from the My Own Health Report project. Am J Prev Med 2014;47:212-9.

42. Graham-Jones P, Jain SH, Friedman CP, Marcotte $\mathrm{L}$, Blumenthal D. The need to incorporate health information technology into physicians' education and professional development. Health Aff (Millwood) 2012;31:481-7.

43. Phillips RL Jr, Kaufman A, Mold JW, et al. The primary care extension program: a catalyst for change. Ann Fam Med 2013;11:173-8. 